Original Article

\title{
Comparison of antioxidant and antibacterial activities of various herbal essential oils: An In vitro study
}

\author{
Arezou Alipour Kakroudi ${ }^{1}{ }^{1}$, Somayeh Rahaiee ${ }^{(1)}{ }^{1 *}$, Hajar Rajaei Litkohi ${ }^{\left(D^{2}\right.}$, \\ Saeed Ghanbari Hassan Kiadeh ${ }^{1}$
}

\begin{abstract}
Background and Aims: Herbal essential oils (EOs) have antimicrobial and antioxidant activities due to the high amount of bioactive compounds; therefore, they are considered good candidates for applications in the food and pharmaceutical industries. The present study aimed to assess the total phenolic content and in vitro comparative study of the biological activities of EOs from different plants (e.g., clove, common sage, savory, and organum).

Materials and Methods: In this experimental study, total phenolic content in EOs was determined, and their antioxidant capacity was measured by the DPPH free radical scavenging method. The components of essential oil were identified using a Gas chromatography-mass spectrometry (GC-MS) device. Moreover, the antibacterial activity of EOs was evaluated by the disk diffusion method, and minimum inhibitory concentration (MIC) and minimum bactericidal concentration (MBC) were evaluated by the broth macro dilution method. Data were analyzed using one-way analysis of variance (ANOVA) and Duncan's multiple range test.
\end{abstract}

Results: The highest content of total phenol $(157.07 \pm 2.37 \mathrm{mg} \mathrm{GAL} / \mathrm{g}$ dry weight) was recorded for EO of organum. Moreover, the highest percentage of free radical scavenging was determined at $98.142 \%$ for organum. The results of GC/MS analysis depicted that monoterpenes were the main compounds of Eos of organum, and the highest value was obtained for the alpha-pinene $(74.04 \%)$. Furthermore, the results of antibacterial activity of EOs demonstrated that the highest zone of inhibition with a diameter of $44 \pm 0.81 \mathrm{~mm}$ was observed for the EO of organum. The lowest values of MIC and MBC were reported as 0.275 and 0.55 $\mathrm{mg} / \mathrm{mL}$ for the EOs of organum and savory against gram-positive Bacillus cereus, respectively.

Conclusion: As evidenced by the results of the current study, the assessed Eos, specifically those of organum, have effective antioxidant and antibacterial activity against bacteria strains, especially grampositive ones, and can be used as safe antimicrobial compounds in food and health products.

Keywords: Antibacterial activity, Antioxidant, Bioactive compounds, Essential oil

Citation: Alipour Kakroudi A, Rahaiee S, Rajaei Litkohi H, Ghanbari Hassan Kiadeh S. [Comparison of antioxidant and antibacterial activities of various herbal essential oils: An In vitro study]. J Birjand Univ Med Sci. 2021; 28(4): 322-334. [Persian]

DOI http://doi.org/10.32592/JBirjandUnivMedSci.2021.28.4.101

Received: July 25, 2021

Accepted: October 19, 2021

\footnotetext{
${ }^{1}$ Department of Microbial Biotechnology, Faculty of Biotechnology, Amol University of Special Modern Technologies, Amol, Iran

${ }^{2}$ Department of Nano Biotechnology, Faculty of Biotechnology, Amol University of Special Modern Technologies, Amol, Iran

* Corresponding author:. Department of Microbial Biotechnology, Faculty of Biotechnology, Amol University of Special Modern

Technologies, Amol, Iran

Tel: +989118675234

Fax: +9811-44154265

E-mail: S.rahaiee@ausmt.ac.ir
} 


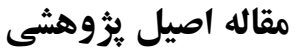

\section{مقايسه فعاليتهاى آنتىاكسيدانى و ضدميكروبى اسانسهاى مختلف تياهى در شرايط آزمايشكاهى}

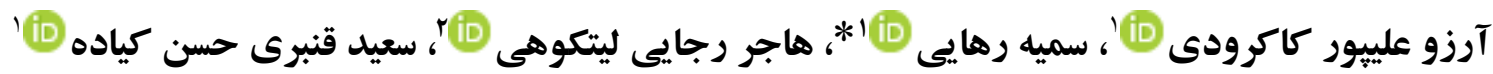

\section{جكيله}

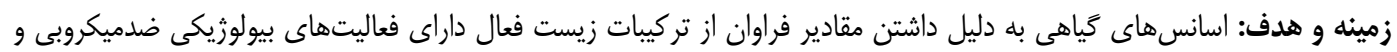

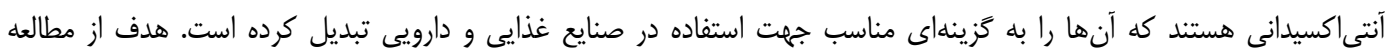

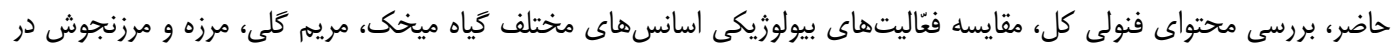

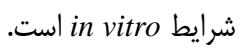

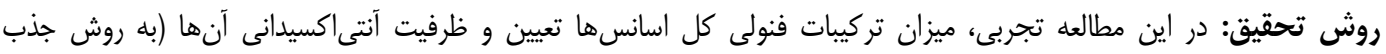

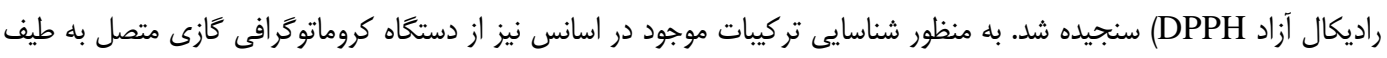

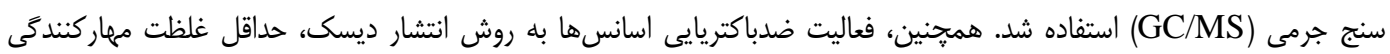

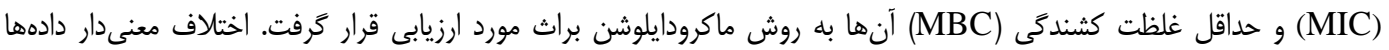

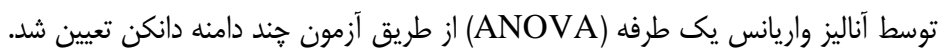

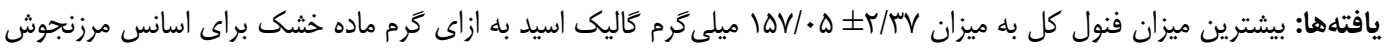

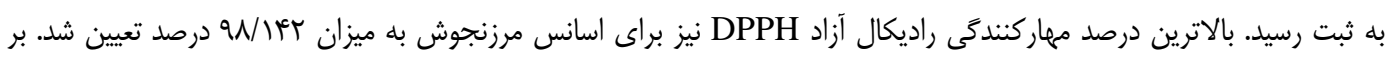

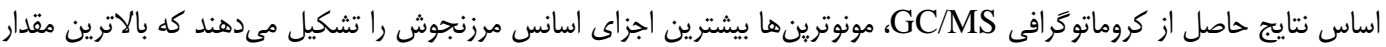

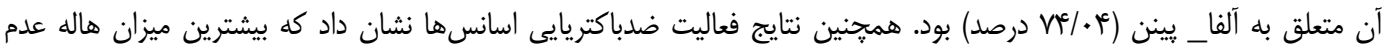

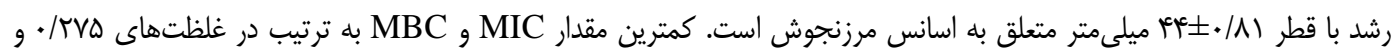

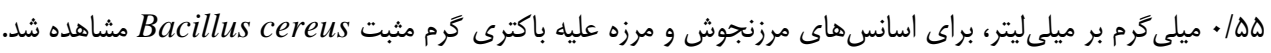

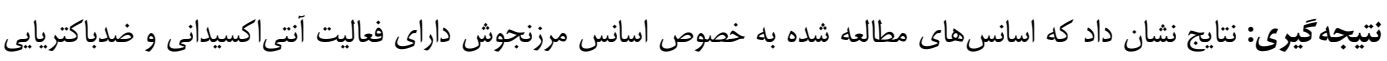

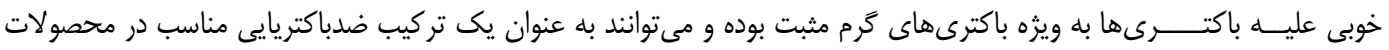

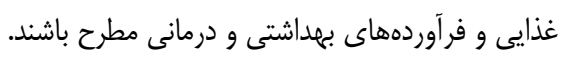

$$
\begin{aligned}
& \text { وازههاى كليدى: فعاليت ضدباكتريايى، آنتى اكسيدانى، تركيبات زيست فعال، اسانس }
\end{aligned}
$$

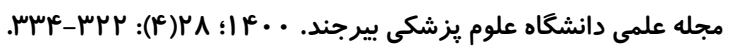

$$
\begin{aligned}
& \text { دريافت: }
\end{aligned}
$$

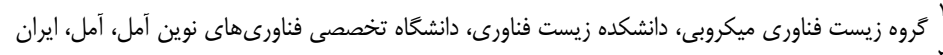

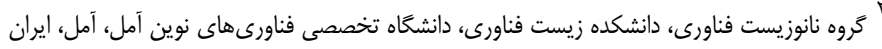

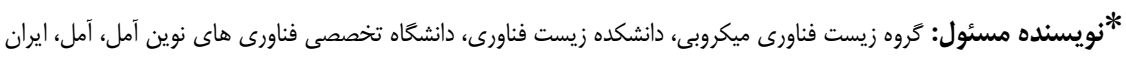

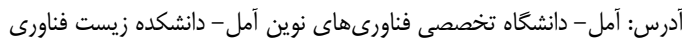

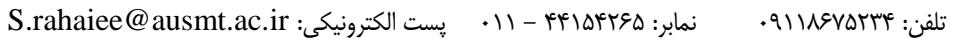


فعاليت آنتىاكسيدانى و ضدميكروبى قابل توجه مىتواند به عنوان

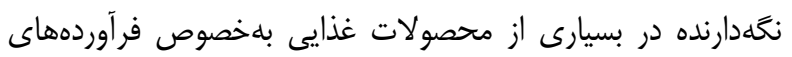

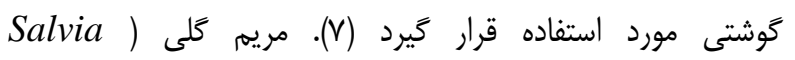
بزر كترين تيره از خانواده Lafficinalis از اسانس آن بلعنوان خاشنى و طعم دهنده در صنايع غذايى استفاده

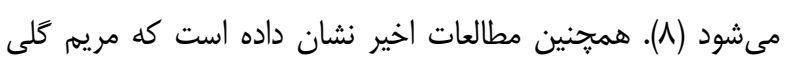

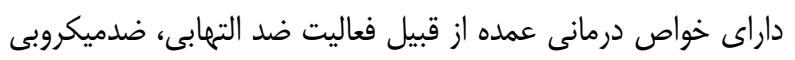

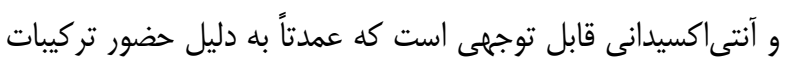
فنلى موجود در آن است (9).) مرزه (Satureja hortensis) نيز

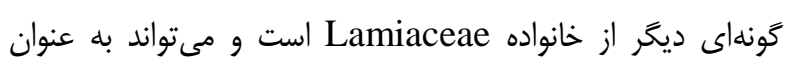
يك طعم دهنده و نتخهدارنده طبيعى در صنايع غذايى به كار كَرفته

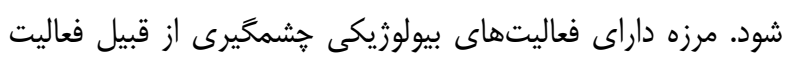

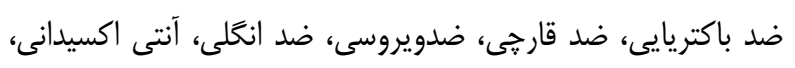

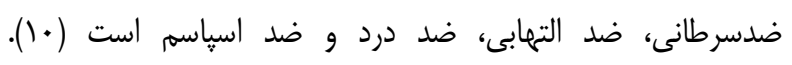

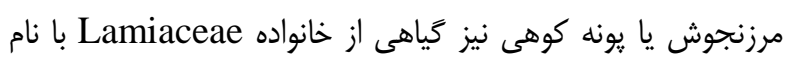
علمى Origanum vulgare مىباشد كه يكى از مهمترين و و يرفروشترين كياهان دارويى در سراسر جهان به شمار مىرود (11).

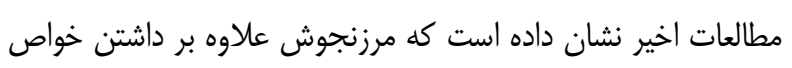

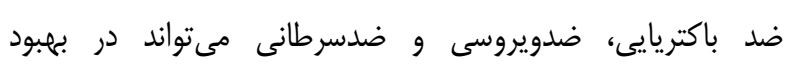
بيمارىهاى قلبى -عروقى، اختلالات كَارشى، ناراحتىهاى تنفسى،

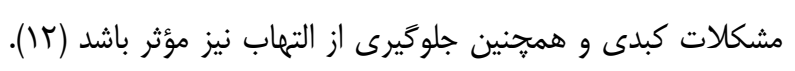

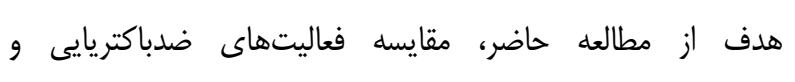

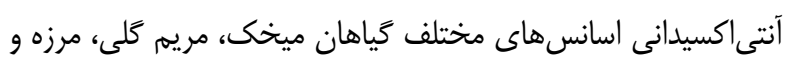
مرزنجوش در شرايط آزمايشعاهى است تا بتوان اسانس مناسب بانس

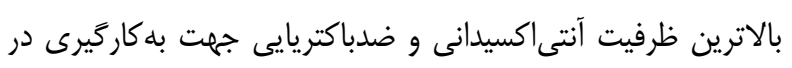
تهيه يوششهاى بستهبندى مواد غذايى شناسايى كرد.

\section{روش تحقيق}

\section{تعيين ميزان فنول كل اسانسها}

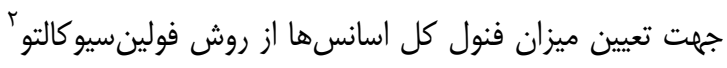

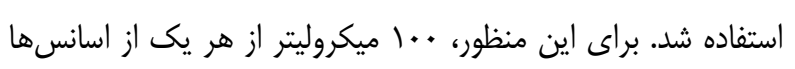

\footnotetext{
${ }^{2}$ Folin-Ciocalteu
}

\section{مقامه}

در سالهاى اخير، عصارهها و به ويزه اسانسهاى گياهى به دليل داشتن مقادير فراوان از تركيبات زيست فعال با عملكرد مؤثر

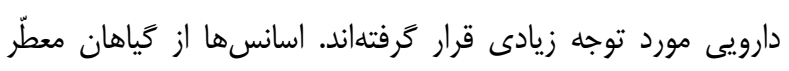

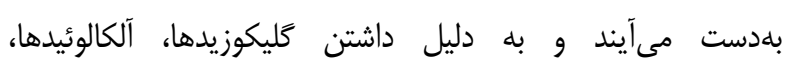

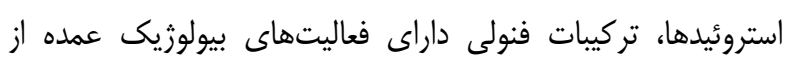

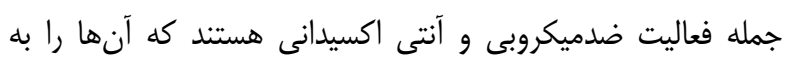

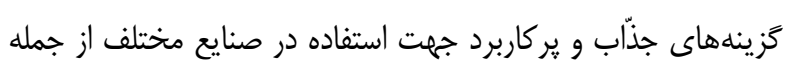
آرايشى-بهداشتى، صنايع غذايى و دارويى و عطرسازى تبديل كرده

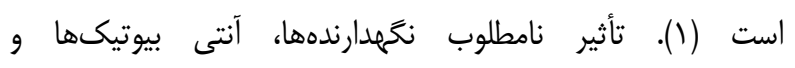

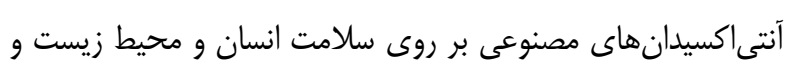

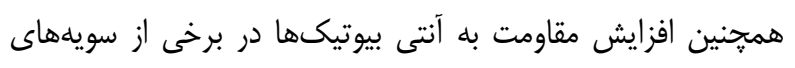

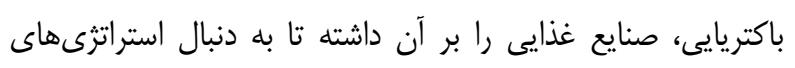

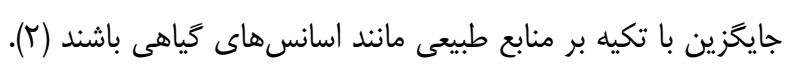

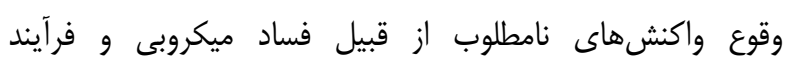

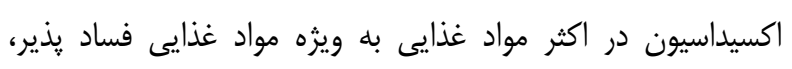

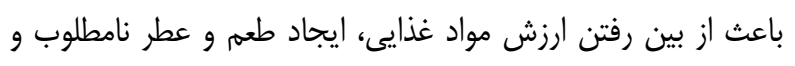

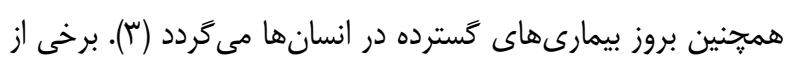
تركيبات زيست فعال موجود در اسانسهاى گياهى غشاى سلولى بردي

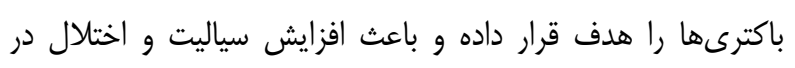

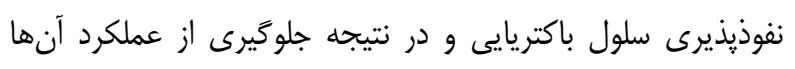

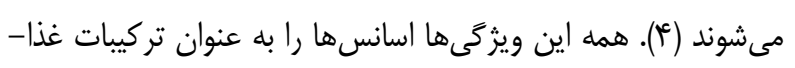
دارو يا نوتراسوتيكال 'هاى بالقوه در صنايع مختلف تبديل كرئ كرده است.

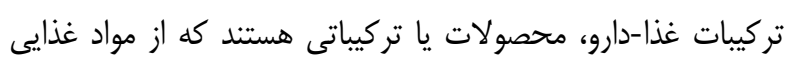

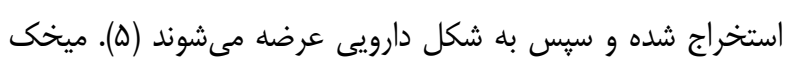
كياهى با رويكرد دارويى از خانواده (Syzygium aromaticum)

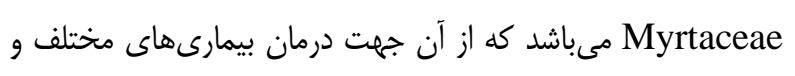
بيمارىهاى ناشى از عفونتهاى مختلف باكتريايى استفاده مى مئدود.

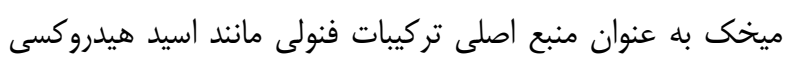

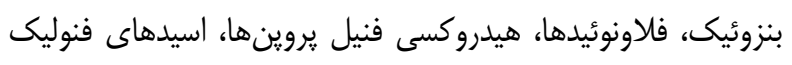

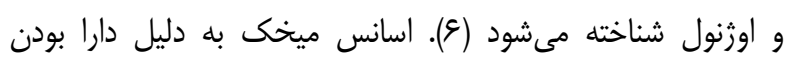

\footnotetext{
${ }^{1}$ Nutraceuticals
} 
محلول با متانول به جهار ميلىليتر رسيد. در ادامه محلول درون فالكونها مخلوط شده و به مدت •r دقيقه در محيط تاريك قرار

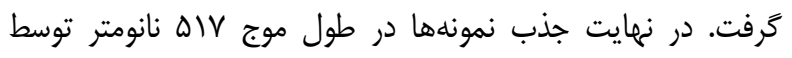

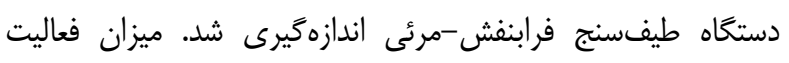

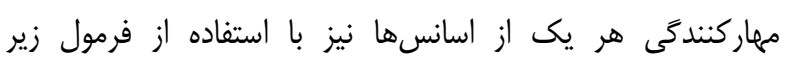
محاسبه كرديد: ميزان مهار راديكال هاى آزاد (\%) كه در اين رابطه AD جذب كنترل و As جذب نمونه حاوى

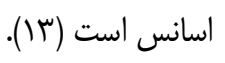

\section{بررسى فعاليت ضدباكتريايى اسانسها}

جهت بررسى فعاليت ضدباكتريايى اسانسها به روشائ روش انتشار ديسك (Disk diffusion)، مطابق با استاندارد (- CLSI M02)

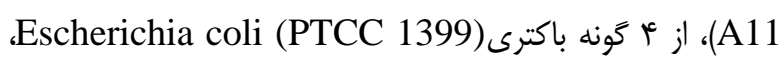
(PTCC 1015) ،Salmonella typhimurium (بالينى) Staphylococcus (ATCC 25923)، Bacillus cereus استفاده كَديد. براى اين منظور، در ابتدا سوسيانسيونهاى aureus باكتريايى رشد يافته و استاندارد شده با محلول نيم مك فارلند تهين منيه

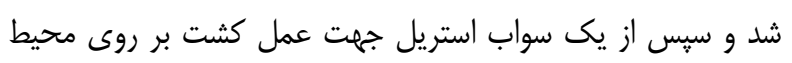

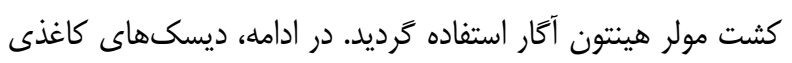

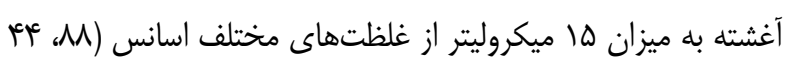

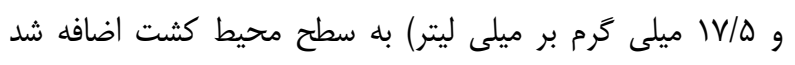

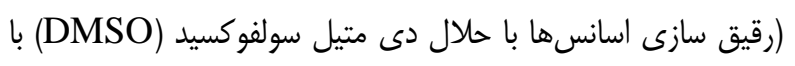

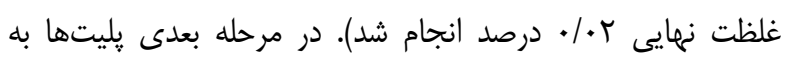

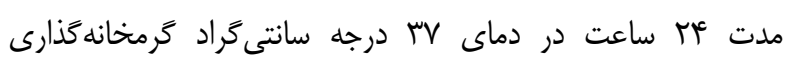

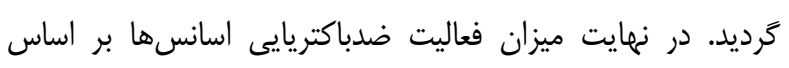

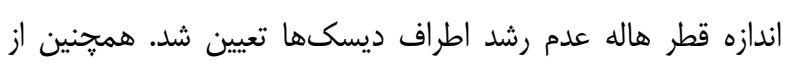

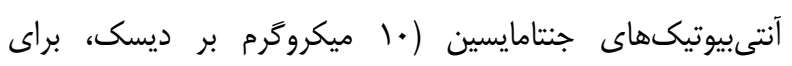

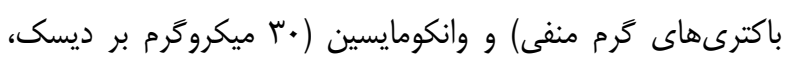

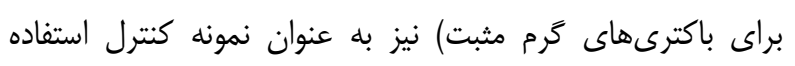

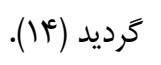

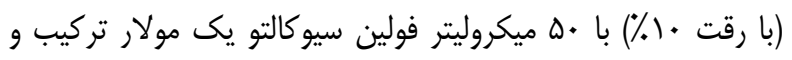

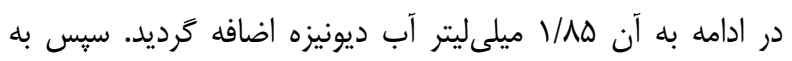

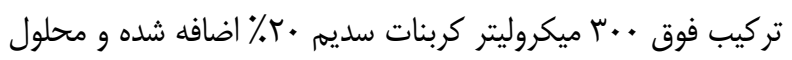

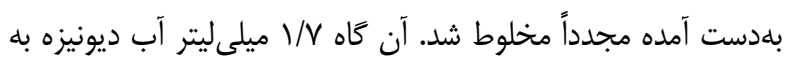
تركيب فوق اضافه شده تا حجم نهايى آن به جهار هزار ميكروليتر

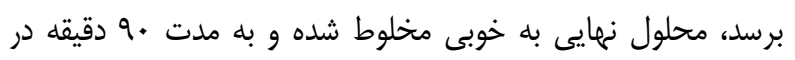

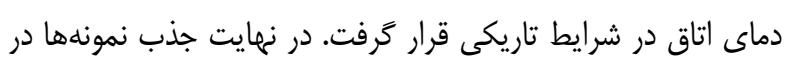

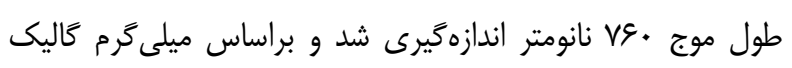
اسيد بر كرم وزن خشك محاسبه گر ديد. همجنين منحنى استاندارد

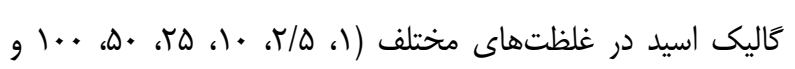

r...

شناسايى تركيبات اسانس با استفاده از دستخاه GC/MS به منظور شناسايى تركيبات اسانس از دستخاه كروماتوكرافى بنى كازى متصل به طيف سنج جرمى (GC/MS) شركت Agilent) (GC7890-MS5975)

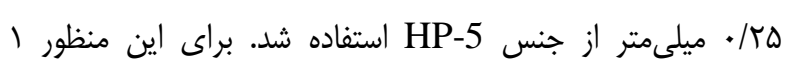

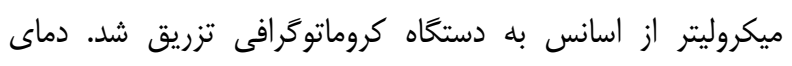

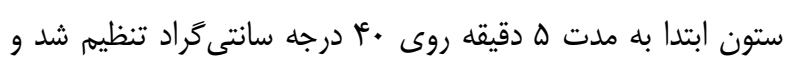

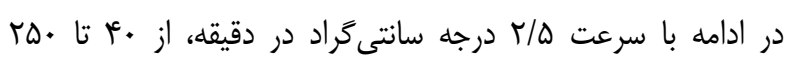

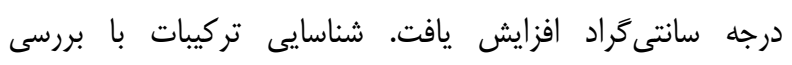
طيفهاى جرمى و مقايسه با طيف جرمى تركيبات استاندارد و

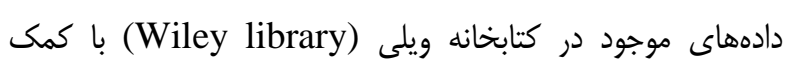
ثابت انديس كواتس صورت كرفت.

بررسى فعاليت آنتى اكسيدانى به روش مهار راديكال آزاد DPPH

به منظور ارزيابى فعاليت مهاركنندگى راديكال آزاد 'DPPH،

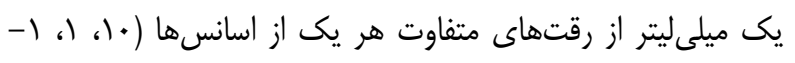

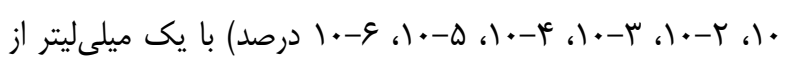

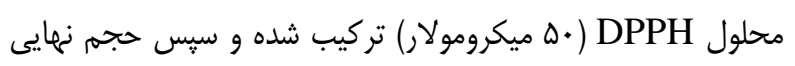

\footnotetext{
${ }^{1}$ 2,2-Diphenyl-1-picrylhydrazyl
} 
يخش و به مدت عاب ساعت كرمخانه گذارى گرديد. كمترين غلظتى

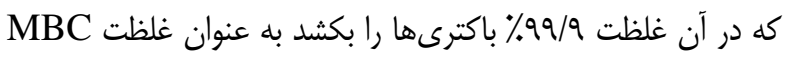
انتخاب كرديد (ه) (1).

\section{تجزيه و تحليل آمارى}

جهت آناليز نتايج بهدست آمده از نرم افزارهاى 26 SPSS و 26 و Origin Pro 2017 آناليز واريانس يك طرفه (ANOVA) با استفاده از آزمون تعقيبى

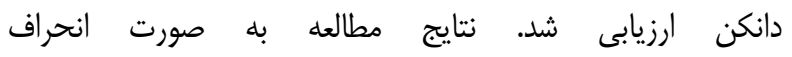

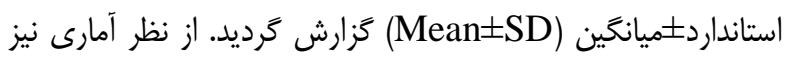

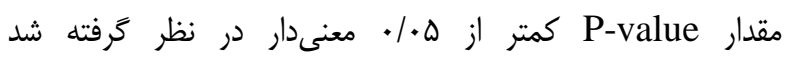
$(\mathrm{P}<\bullet / \bullet)$

مطالعه حاضر پِ از تأييد كميته اخلاق دانشعاه تخصصى ها. فناورىهاى نوين آمل با كد Ir.ausmt.rec.1400.09 انجام شد.

\section{يافته ها}

\section{محتواى فنول كل}

مقايسه ميانخين دادهها نشان داد كه بيشترين و كمترين ميزان فنول كل بلهترتيب مربوط به اسانس مرزنجوش با مين ميزان

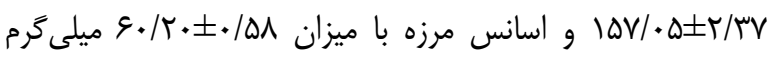
كاليى اسيد به ازاى كرم ماده خشك بوده است. مقايسه ميزان تركيبات فنولى كل هر يك از اسانسها در جدول آمآده است است.
تعيين حداقل غلظت بازدارندكى (MIC) و كشندكى

(MBC)

جهت تعيين حداقل غلظت بازدارندگى (MIC) از روش

) رقيقسازى در محيط مايع در مقياس ماكرو Broth Macro)

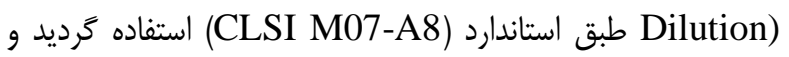

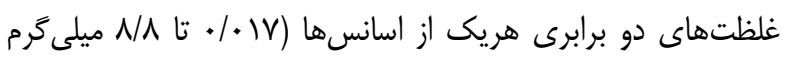
بر ميلىليتر) تهيه شد. بدين منظور، يك ميلى ليتر محيط كشت مولر هينتون براث در لولههاى أزمايش ريخته و سبس به به اولين لوله

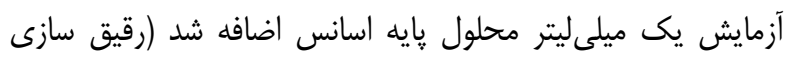

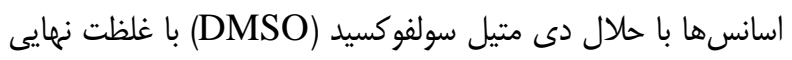

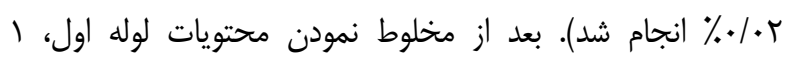

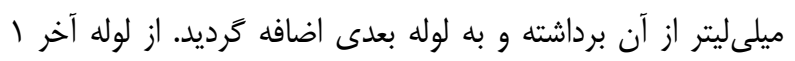

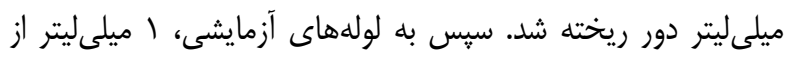

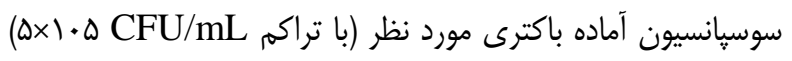

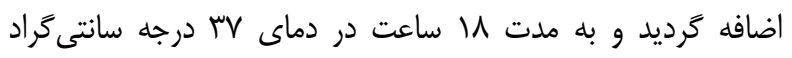

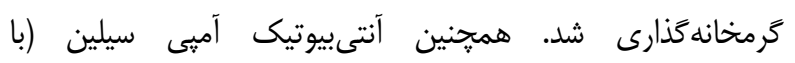

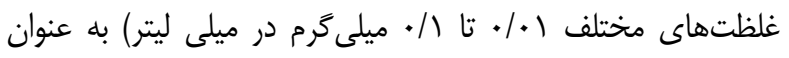

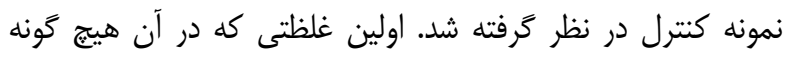
كدورتى ناشى از رشد باكترى مشاهده نشد به عنوان حداقل غلظت

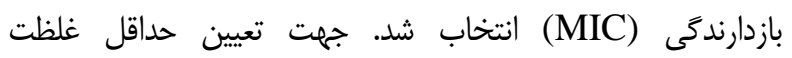

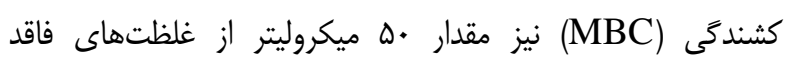

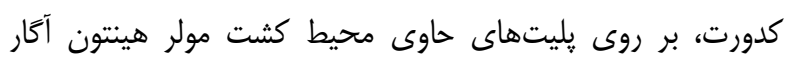

جدول (- مقايسه ميزان فنول كل اسانسهاى مختلف

\begin{tabular}{|c|c|c|c|c|}
\hline ميخك & مريم كلى & مرزنجوش & مرزه & \\
\hline$V \Delta / \wedge \varepsilon \pm 1 / / \varepsilon^{c}$ & $1.9 / 9 q^{\prime} \pm . / 9 r^{b}$ & $\mid \Delta V / \cdot \Delta \pm r / r V^{a}$ & $9 \cdot / r \cdot \pm \cdot / \Delta \Lambda^{d}$ & فنول كل \\
\hline
\end{tabular}

* در هر رديف ميانكينهايى كه حداقل داراى يك حرف مشابه هستند، بر مبناى آزمون حند دامنهى دانكن در سطح هـ/. تفاوت معنى دارى ندارند. نتايج به صورت ميانكين Iانحراف استاندارد كزارش شده است.

افزايش يافته است. طبق نتايج حاصل از مقايسه ميانغين تيمارها

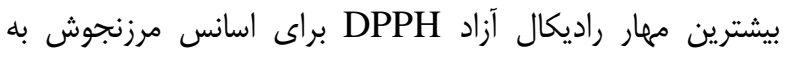

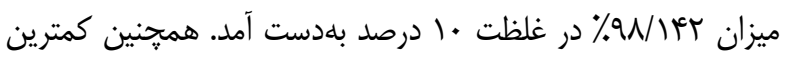

ميزان فعاليت مهار كنندَّى راديكال آزاد (DPPH) ارزيابى فعاليت آنتى|كسيدانى اسانسها به روش جذب راديكال

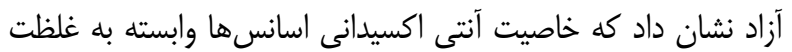


باكترىهاى مورد مطالعه در اين يزوهش را دارا بود. همجنين

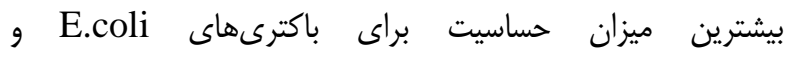
Staphylococcus aureus مرزه به ثبت رسيد. باكترى كرم منفى Salmonella نيز بيشترين ميزان حساسيت را در برابر اسانس مئس

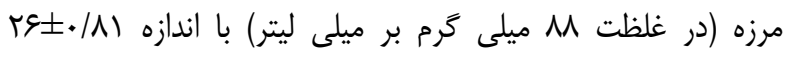

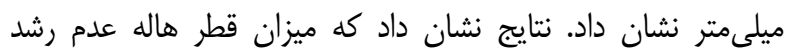

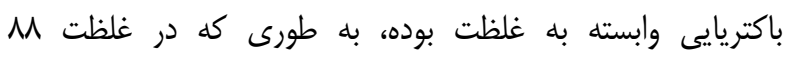
ميلى ترم بر ميلىليتر هر يك از اسانسها، بيشترين اندازه قطر هاله بـانه عدم رشد مشاهده شده است. جدول r مقايسه كامل قطر هالههاى مئي عدم رشد باكتريايى اسانس هاى مختلف را نشان مى دهد.
ميزان مهاركنندگى راديكال آزاد نيز براى اسانس ميخك به ميزان

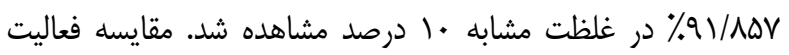

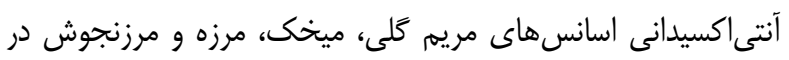
تصوير آمده است.

$$
\text { فعاليت ضدباكتر يايى }
$$

بررسى ميانكَين قطر هالههاى عدم رشد نشان داد كه اسانسهاى مورد مطالعه در اين يثوهش، اثرات ضدباكتريايى قابل فران توجهى را در برابر گونههاى باكتريايى ذكر شده نشان دادند. به ديه

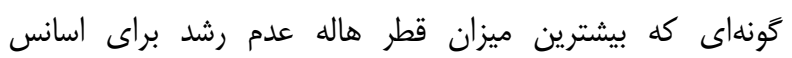

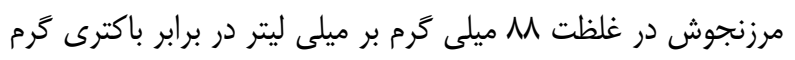

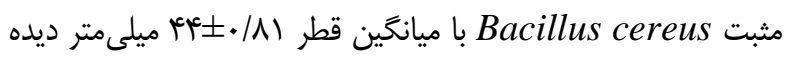

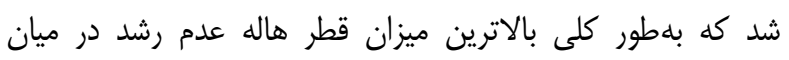

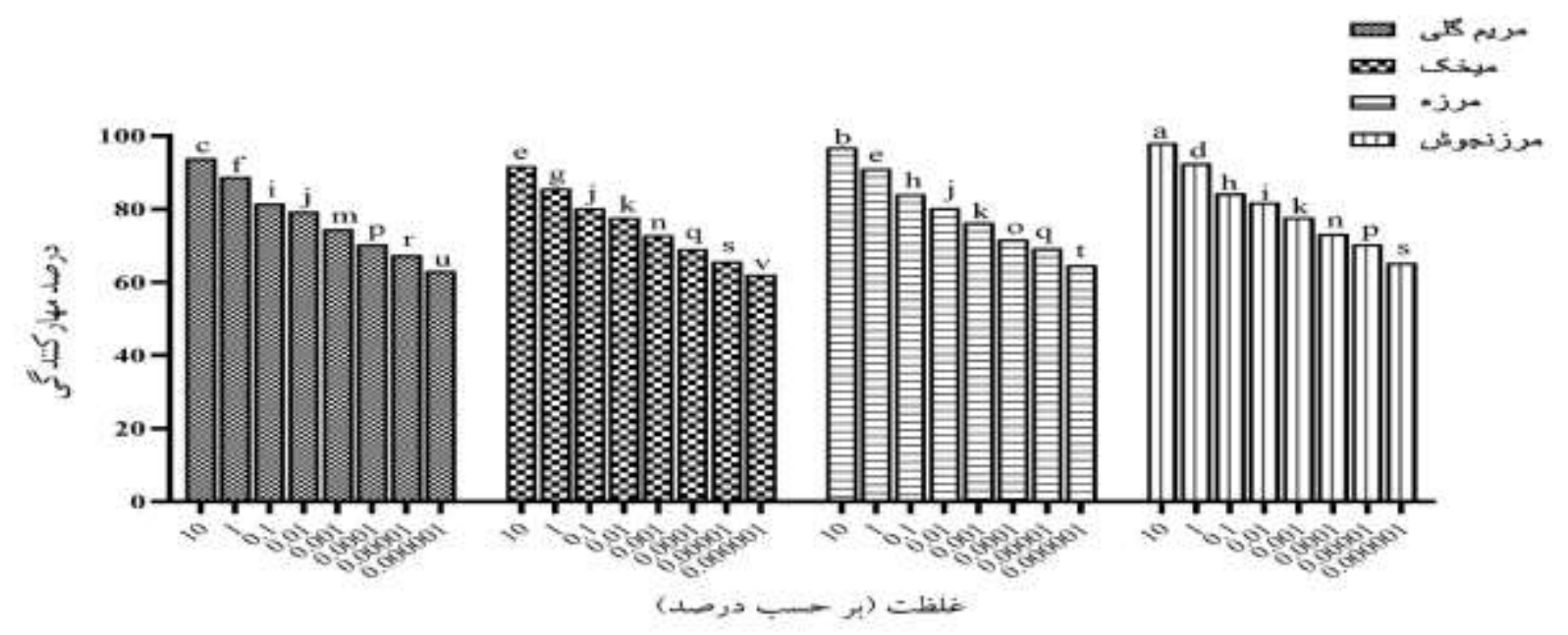

تصوير ا - ميزان فعاليت آنتىاكسيدانى اسانسهاى مختلف تياهى (ميانكَينهاى داراى حروف مشابه بر اساس آزمون جند دامنهى دانكن در سطح ه./ تفاوت معنى دارى ندارند)

Bacillus و Staphylococcus aureus باكترىهاى گرم مثبت

$$
\text { cereus }
$$

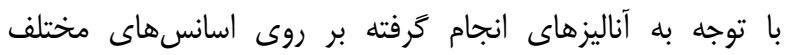

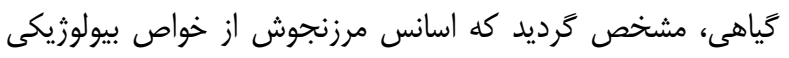
بهترى برخوردار است؛ لذا به منظور مطالعه و شناسايى تركيبات

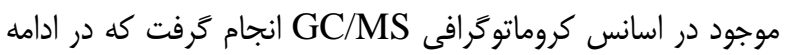
نتايج بهدست آمده ذكر شده است.
حداقل غلظت بازدارندكى و كشندكى (MBC و ميزان MBC و MIC Mر يك از اسانسها در مقابل سويههاى باكتريايى مورد ارزيابى قرار كرفت. نتايج حاكى از آن بود

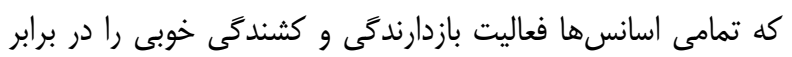

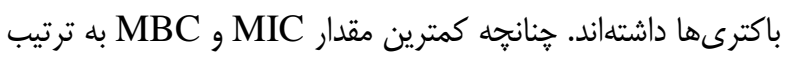

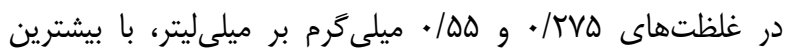

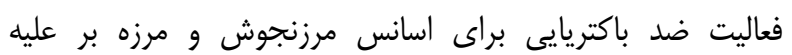




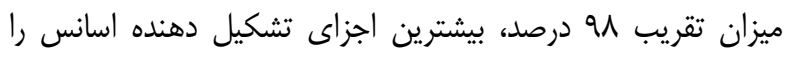

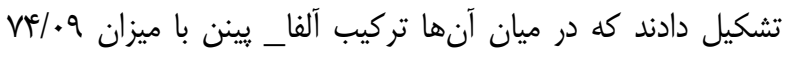

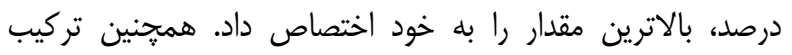

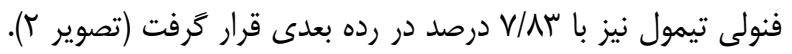

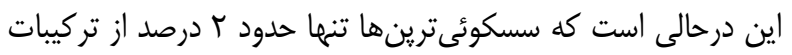
تشكيل دهنده اسانس را شامل شدند كه از مهمم ترين آنها مى كتوان به تركيب شيميايى كاريوفيلين اشاره كرد.
شناسايى تركيبات اسانس با استفاده از دستگًاه GC/MS

تركيبات موثره موجود در اسانس مرزنجوش توسط دستخاه

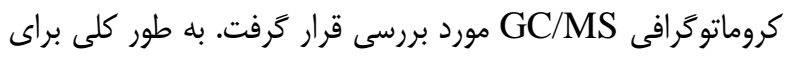

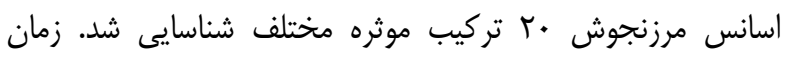

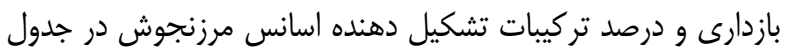

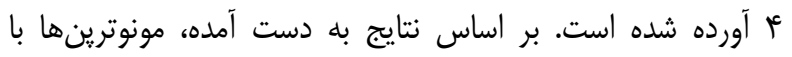

جدول ץ - قطر هاله عدم رشد باكترىها در مقابل غلظتهاى مختلف اسانسها (بر حسب ميلىمتر)

\begin{tabular}{|c|c|c|c|c|c|}
\hline \multirow{2}{*}{ آنتى بيوتيك } & \multicolumn{3}{|c|}{ غلظت اسانسها برحسب ميلى گرم بر ميلىليتر } & \multirow{2}{*}{ اسانس } & \multirow{2}{*}{ سويه باكترى } \\
\hline & $\mathrm{IV} / \mathrm{\Delta}$ & pi & $M$ & & \\
\hline$(\mathrm{GM}) \| \mathrm{f} \pm \cdot / \cdot$ & $\mid r / \& V \pm \cdot / \mathcal{A} V^{b c}$ & ז'. & 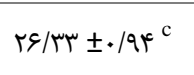 & مرزنجوش & \multirow{4}{*}{$\begin{array}{c}\text { E.coli } \\
\text { (PTCC 1399) }\end{array}$} \\
\hline$(\mathrm{GM}) \| \mathfrak{} \pm \cdot /$. & $11 / q V \pm \cdot /\left.9\right|^{\mathrm{cd}}$ & $r r / \& \& \pm \cdot / \mathscr{c} V^{b c}$ & $r V / g V \pm \cdot / q r^{c}$ & مرزه & \\
\hline$(\mathrm{GM}) \| \mathrm{f} \pm \cdot / \cdot$ & $V / \& q \pm \cdot / q^{\mathrm{e}}$ & 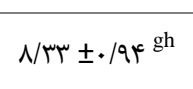 & $1.19 V \pm . / 9)^{h}$ & 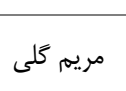 & \\
\hline$(\mathrm{GM}) \| f \pm \cdot / \cdot$ & $V / \& 9 \pm \cdot / \not V^{e}$ & $1 \cdot / \mu س \pm . / F V^{f}$ & $\mid f / q V \pm \cdot / F^{g}$ & ميخى & \\
\hline$(\mathrm{VA}) 1 f \pm \cdot / \cdot$ & $\Lambda / r \Psi \pm . / q \uparrow^{e}$ & $r / / r \pm 1 / r r^{c d}$ & $r / / \& \& \pm \cdot / \& V^{b}$ & مرزنجوش & \multirow{4}{*}{$\begin{array}{c}\text { Staphylococcus aureus } \\
\text { (ATCC 25923) }\end{array}$} \\
\hline$(\mathrm{VA}) 1 f \pm \cdot / \cdot$ & $\mid r / \& V \pm I / \mu^{b}$ & $r F / r+. / q F^{b}$ & $M \pm \cdot|\wedge|^{b}$ & مرزه & \\
\hline$(\mathrm{VA}) 1 \uparrow \pm \cdot / \cdot$ & $\wedge \pm \cdot|\wedge|^{e}$ & $9 \pm 1 / \uparrow^{\text {fgh }}$ & $1 \cdot \pm \cdot|\Lambda|^{h}$ & 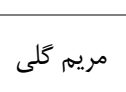 & \\
\hline$(\mathrm{VA}) 1 f \pm \cdot / . \cdot$ & 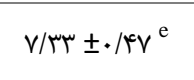 & $q / \& \vee \pm * / \propto \vee^{\mathrm{fg}}$ & | & ميخى & \\
\hline$(\mathrm{VA}) 19 \pm . /$. & $1 \cdot / r \pm . / 4 \gamma^{d}$ & $r q \pm \cdot / 1)^{a}$ & $\left.|+ \pm \pm \cdot| \Lambda\right|^{a}$ & 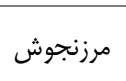 & \multirow{4}{*}{$\begin{array}{l}\text { Bacillus cereus } \\
\text { (PTCC 1015) }\end{array}$} \\
\hline$(\mathrm{VA}) 19 \pm \cdot / \cdot$ & 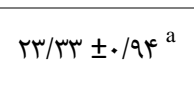 & $r N / r T \pm \cdot / Q r^{a}$ & $M I / \mu \pm ו / M^{b}$ & مرزه & \\
\hline$(\mathrm{VA}) 19 \pm \cdot / \cdot$ & $V / \mu \pm \cdot / 4 V^{e}$ & $\wedge \pm \cdot / \wedge)^{\mathrm{gh}}$ & $|\xi / \xi V \pm 1 / r|^{\mathrm{fg}}$ & 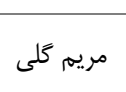 & \\
\hline$(\mathrm{VA}) 19 \pm \cdot / \cdot \cdot$ & $\wedge \pm \cdot / \wedge 1^{e}$ & $1 f \pm .10^{\mathrm{e}}$ & $|V \pm \cdot / \Lambda|^{f}$ & 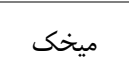 & \\
\hline$(\mathrm{GM}) \mathrm{rl} \pm \cdot / \cdot$ & $\mathrm{V} / \not \& \pm \cdot / \not V^{\mathrm{e}}$ & $M / G V \pm . / K V^{\mathrm{e}}$ & 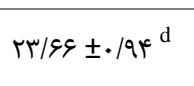 & 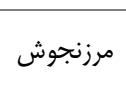 & \multirow{4}{*}{$\begin{array}{c}\text { Salmonella typhimurium } \\
\text { (بالينىى }\end{array}$} \\
\hline$(\mathrm{GM}) r \pm \cdot / \cdot \cdot$ & $\mid r / \Psi \Psi \pm ו T f^{b c}$ & $\left.r| \pm \cdot| 1\right|^{d}$ & $r \varphi \pm \cdot /\left.\Lambda\right|^{c}$ & مرزه & \\
\hline$(\mathrm{GM}) r \mathrm{r} \pm \cdot / \cdot$ & $v \pm . / . e^{e}$ & $V / T H \pm / F V^{h}$ & $q / \& V \pm \cdot / q V^{h}$ & 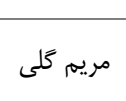 & \\
\hline 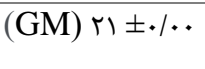 & $V / \& q \pm \cdot / \not V^{e}$ & $1 \cdot / r^{\prime} \pm \cdot / V^{f}$ & $r \cdot \pm \cdot / \Lambda)^{\mathrm{e}}$ & ميخى & \\
\hline
\end{tabular}

* در هر ستون ميانكينهايى كه حداقل داراى يك حرف مشابه هستند، بر مبناى آزمون קند دامنهى دانكن در سطح هـ/. تفاوت معنىدارى ندارند. نتايج به صورت

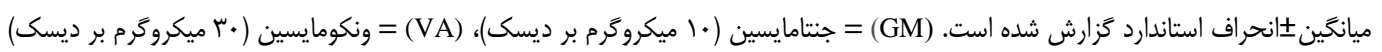


جدول سـ- حداقل غلظت بازدارندَّى و كثندَّى (بر حسب ميلى ترم بر ميلىليتر)

\begin{tabular}{|c|c|c|c|c|c|c|c|c|c|c|}
\hline \multicolumn{2}{|c|}{ آمبى سيلين } & \multicolumn{2}{|c|}{ ميخك } & \multicolumn{2}{|c|}{ مريم كلى } & \multicolumn{2}{|c|}{ مرزه } & \multicolumn{2}{|c|}{ مرزنجوش } & \multirow{2}{*}{ سويه باكترى } \\
\hline MBC & MIC & MBC & MIC & MBC & MIC & MBC & MIC & MBC & MIC & \\
\hline$\cdot /^{\mathrm{f}}$ & $\cdot 1 \cdot 0^{\mathrm{g}}$ & $r / \kappa^{a}$ & $r / r^{b}$ & $r / \kappa^{\mathrm{a}}$ & $r / r^{b}$ & $1 / 1^{c}$ & $\cdot / \Delta \Delta^{\mathrm{d}}$ & $1 / 1^{c}$ & $\cdot / \Delta \Delta^{\mathrm{d}}$ & $\begin{array}{c}\text { E.coli } \\
\text { (PTCC 1399) }\end{array}$ \\
\hline$\cdot / \cdot 0^{\mathrm{g}}$ & $.1 \cdot r^{\mathrm{h}}$ & $r / r^{b}$ & $1 / 1^{c}$ & $r / r^{\mathrm{b}}$ & $1 / 1^{c}$ & $\cdot / \Delta \Delta^{\mathrm{d}}$ & $\cdot / T V \Delta^{\mathrm{e}}$ & $\cdot / \Delta \Delta^{\mathrm{d}}$ & $\cdot / T V \Delta^{\mathrm{e}}$ & 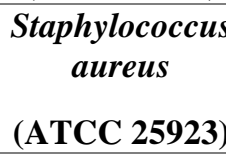 \\
\hline$\cdot / \cdot \Delta^{\mathrm{g}}$ & $\cdot / \cdot r^{\mathrm{h}}$ & $r / r^{b}$ & $1 / 1^{c}$ & $r / r^{\mathrm{b}}$ & $1 / 1^{c}$ & $\cdot / \Delta \Delta^{\mathrm{d}}$ & $\cdot / T V \Delta^{e}$ & $\cdot / \Delta \Delta^{\mathrm{d}}$ & $\cdot / T V \Delta^{\mathrm{e}}$ & $\begin{array}{l}\text { Bacillus cereus } \\
\text { (PTCC 1015) }\end{array}$ \\
\hline$\cdot 1^{\mathrm{f}}$ & $\cdot / \cdot \Delta^{g}$ & $r / \kappa^{a}$ & $r / r^{b}$ & $r / \kappa^{a}$ & $r / c^{a}$ & $1 / 1^{c}$ & $\cdot / \Delta \Delta^{\mathrm{d}}$ & $1 / 1^{c}$ & $\cdot / \Delta \Delta^{\mathrm{d}}$ & $\begin{array}{c}\begin{array}{c}\text { Salmonella } \\
\text { typhimurium }\end{array} \\
\text { (بالينى) }\end{array}$ \\
\hline
\end{tabular}

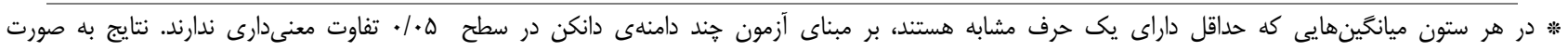
ميانكين ذانحراف استاندارد كزارش شده است.

جدول f FC/MS تركيبات شناسايى شده اسانس مرزنجوش توسط آناليز

\begin{tabular}{|c|c|c|c|c|c|}
\hline شاخص بازدارى & شاخص بازدارى & زمان بازدارى & درصد & نام تركيب & رديف \\
\hline 919 & 991 & S/MAF &.$/ \cdot r$ & $\beta$-Myrcene & 1 \\
\hline 91. & aTe & $g / M F i$ & .1 .9 & Tricyclene & $r$ \\
\hline $9 \pi$ & qभ. & $s / Q \cdot r$ &.$/ 14$ & $\alpha$-Thujene & r \\
\hline q४q & q४q & s/Ne & $v e / .9$ & $\alpha$-Pinene & i \\
\hline 991 & $90 F$ & $\mathrm{~V} / \mathrm{IFA}$ &.$/ \Delta T$ & Camphene & $\Delta$ \\
\hline qrr & 9v9 & $N \cdot 9 \mathrm{~V}$ & I/Ar & $\beta$-Pinene & 8 \\
\hline 991 & 979 & N/994 &.$/ r r$ & $\beta$-Myrcene & v \\
\hline $1 . \mathrm{rA}$ & 1.4. & $9 / 4 \times 4$ & $\cdot \pi$ & $\Delta$-3-Carene & $\wedge$ \\
\hline 1.11 & 1.18 & $9 / 9 \Delta 9$ & $\cdot / \kappa$ & a.-Terpinene & 9 \\
\hline $1 . r 9$ & $1 . r 9$ & Q/^)ৎ & $r / \uparrow \wedge$ & Cymene & 1. \\
\hline 1.94 & 1.9. & $11 / \mu r \Lambda$ & $1 / \Delta T$ & $\gamma$-Terpinene & 11 \\
\hline 1191 & 1.19 & IT/GG &.$/ 19$ & $\alpha$-Terpinolene & ir \\
\hline 119. & 1119 & $\mid \varepsilon / K^{\prime} \mu$ & $\cdot / \pi$ & 4-Terpineol & Ir \\
\hline IKFA & ITFE & 19/ब9T & 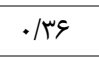 & Carvacrol Methyl ether & If \\
\hline Ir.t & ITNS & Tr/QIT & V/Ar & Thymol & 10 \\
\hline 1799 & 1791 & tr/QIS & ه/१ & Carvacrol & 19 \\
\hline IFEs & $|r \Delta|$ & $T F /$ TqF & $\cdot / \kappa$ & Thymol acetate & iv \\
\hline 1411 & 1919 & TV/OTY & $\cdot / \mathrm{V}$ & Trans-Caryophyllene & M \\
\hline 1994 & $|f 4|$ & TN/TGK & צ צ & (+)-Aromadendrene & 19 \\
\hline IQMM & $10 \wedge 1$ & Tr/GDS &.$/ 49$ & Caryophyllene oxide & r. \\
\hline
\end{tabular}




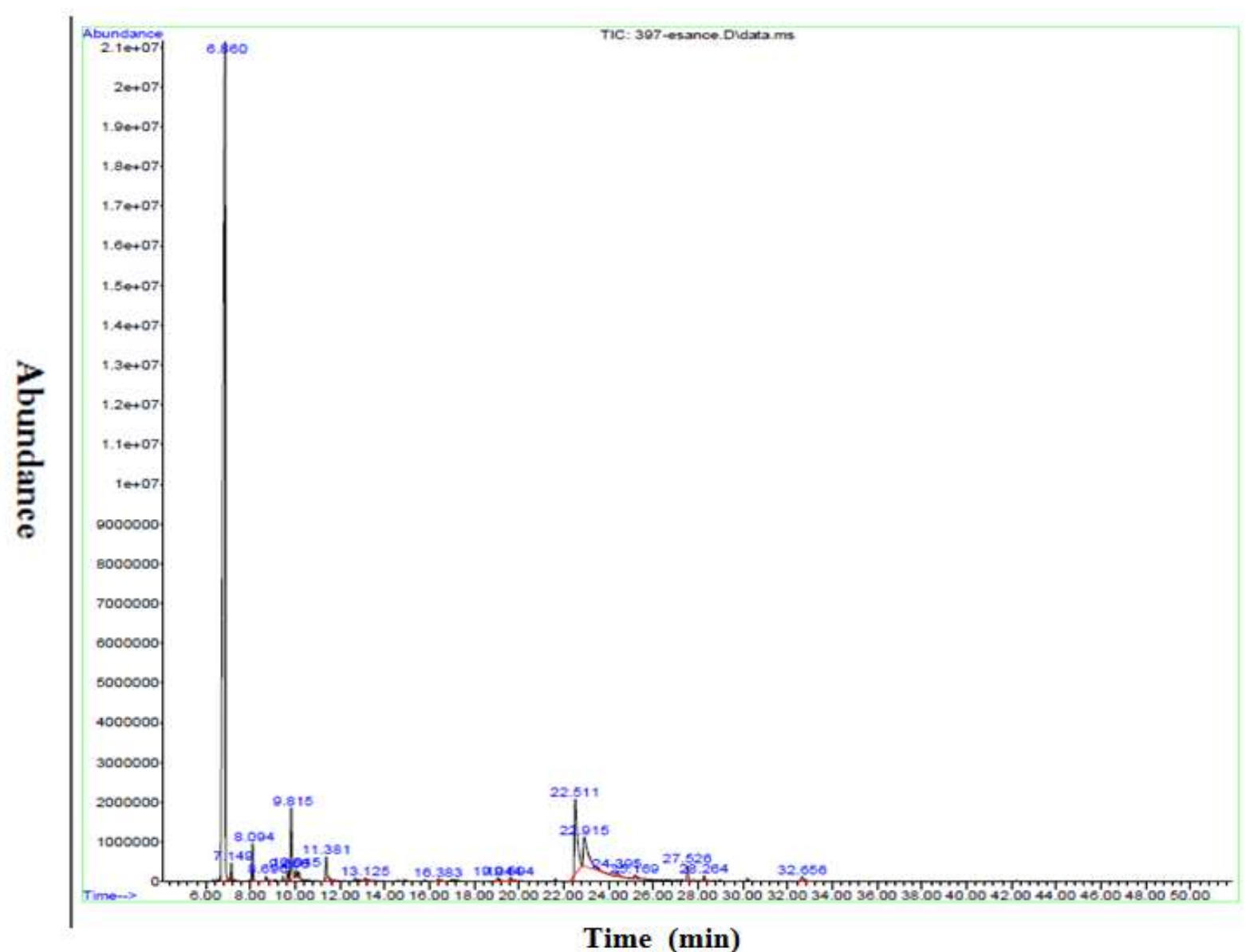

Time (min)

تصوير r- نموداركروماتوتر افى GC/MS اسانس مرزنجوش

فنلى استوار مىباشد. يتانسيل بالاى تركيبات فنولى جهت از بين

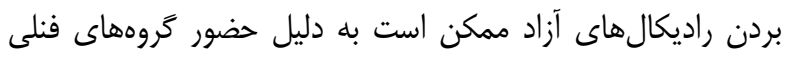

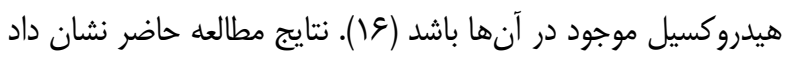
كه اسانسهاى مورد بررسى، حاوى مقادير قابل توجهى از تركيبات

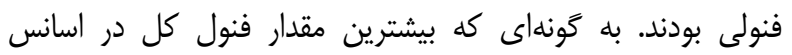

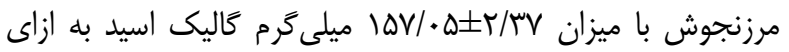
كرم ماده خشك مشاهده شد. در مطالعهاى كه Raeisi و همكاران

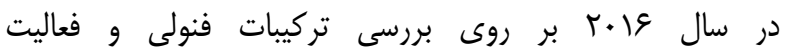
آنتى اكسيدانى اسانس هاى مرزنجوش، باديان رومى و زيره سبز انجام دادند مشخص شد كه اسانس مرزنجوش داراى تركيبات فنولى بالا

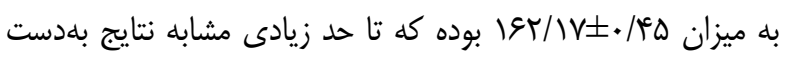
آمده در يثوهش حاضر است. موقعيت جغرافيايى، شرايط آب و و

در سالهاى اخير تأثير عصاره و به ويزه اسانسهاى گياهى بر روى سلامت انسان و محيط زيست مورد توجه زيادى قرار كرفته

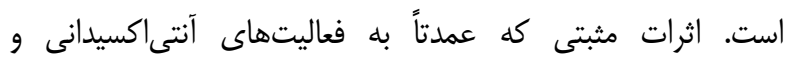
ضدراديكالى تركيبات فيتوشيميايى موجود در آنها نسبت داده

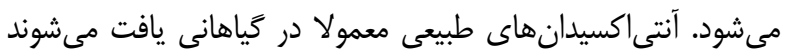
كه داراى تركيبات فنولى و فلاونوئيدى بالايى هستند. در مطالعه

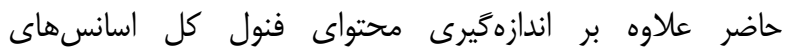
مرزنجوش، مرزه، مريم كلى و ميخك، ظرفيت آنتىاكسيدانى آنها

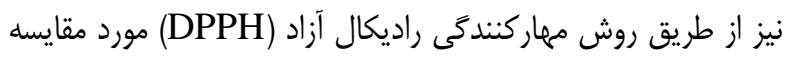

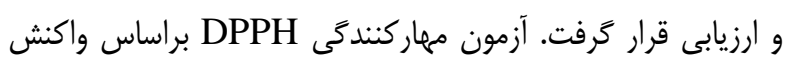
راديكال آزاد DPPH با تركيبات دهنده هيدروزن از قبيل تركيل تركيبات 
داشتن خواص متنوع بيولوزيكى و دارويى مانند آنتىاكسيدانى،

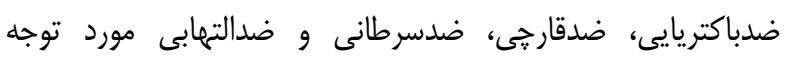
فراوانى قرار كرفته است؛ به طور كلى فعاليت آنتىاكسيدانى آلفا-

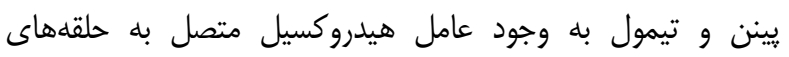

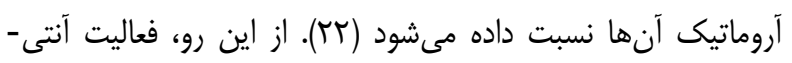

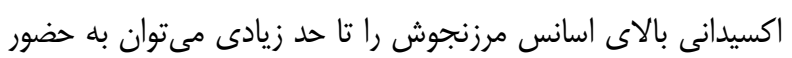
اين تركيبات نسبت داد.

همجنين فعاليت ضدباكتريايى اسانسها نيز در برابر جهار سويه

S. typhimurium, E.coli، S. aureus ،B.cereus باكتريائ مورد ارزيابى و مقايسه قرار گرفت. باكترىهاى مورد مطالعه در اين

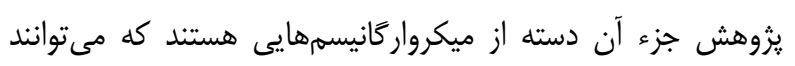

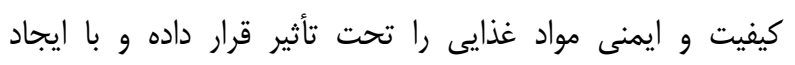
مسموميتهاى غذايى مشكلات عديدهاى را براى انسان به وجود إنى

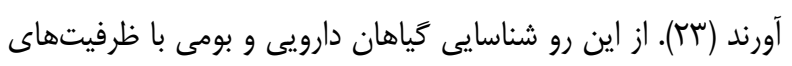

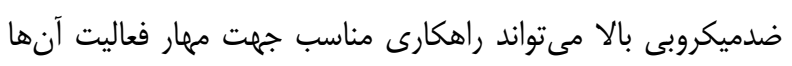
تلقى كردد. نتايج فعاليت ضدميكروبى اسانس هاى مورد مطالعه نشان داد كه هر جهار سويه باكتريايى نسبت به اسانسها حساس بودهاند.

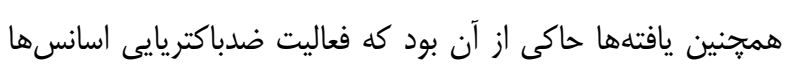

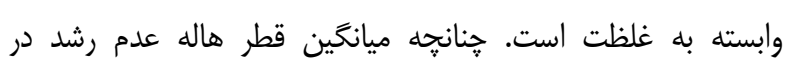

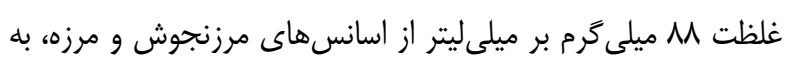

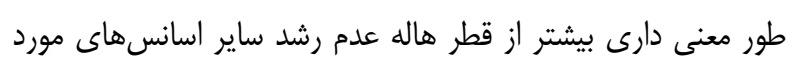

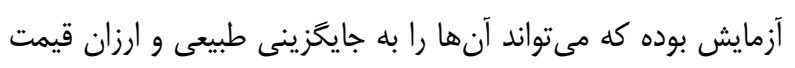

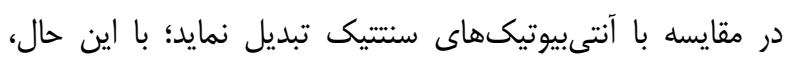

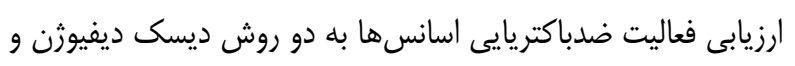

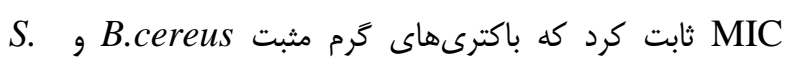
و S. typhimurium نسبت به باكترىهاى كرم منفى aureus

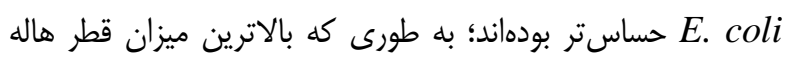
عدم رشد و همجنين كمترين مقدار MIC و MBC

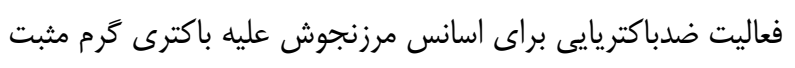
B.cereus

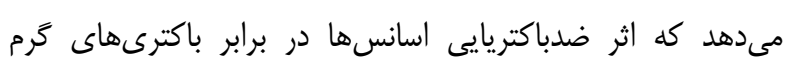
مثبت بيشتر از باكترىهاى كرم منفى مىباشد. اين امر تا حد زيادى
هوايى، فصل برداشت و نوع خاك از جمله عواملى است كه مىتواند

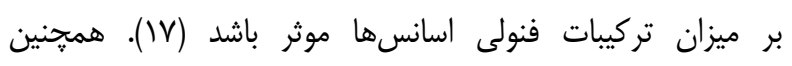

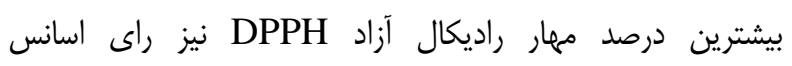

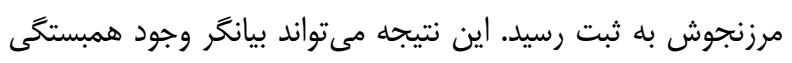
بين محتواى تركيبات فنولى و ظرفيت آنتى اكسيدانى در اسانسهاى

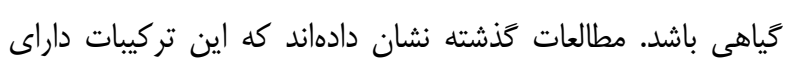
فعاليتهاى ضدالتهابى و آنتى اكسيدانى قابل توجهى هستند (1) (1).

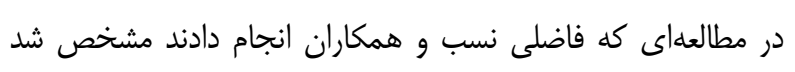

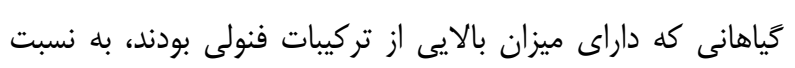

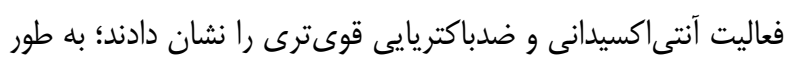
كلى مطالعات نشان دادهاند كه هر خه مقدار تركيبات فنوليك موجود

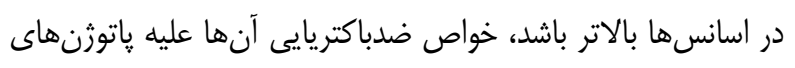

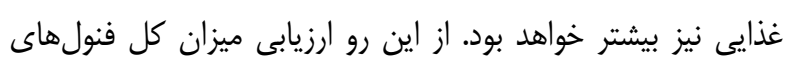

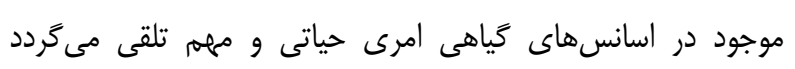

همجنين شناسايى تركيبات موثره اسانس مرزنجوش توسط دستخاه كروماتوكرافى GC/MS نشان داد كه تركيبات منوترينى

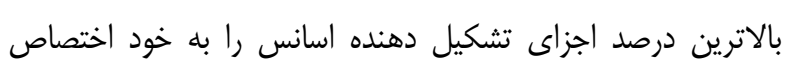

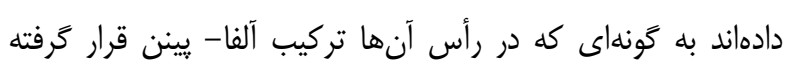

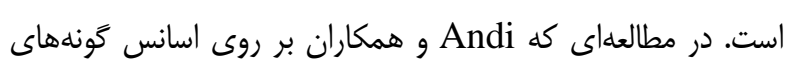
ديخر مرزنجوش انجام دادند، تركيبات تشكيل دهنده غالب در مرحله

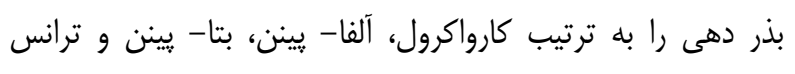

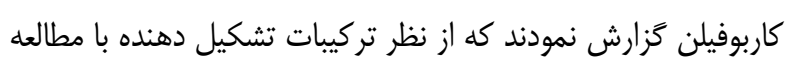

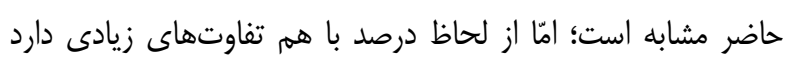
كه اين امر را مىتوان به عوامل متعددى از قبيل نوع گَونه، مراحل

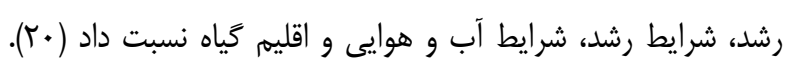

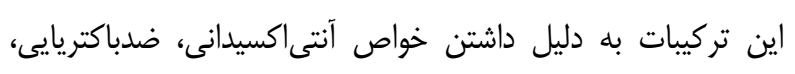
ضدويروسى و ضدالتهابى قابل توجه، جزء تركيبات منحصر به فرد و و يركاربرد در صنايع غذايى محسوب مىشوند. آلفا-يينن با تأثير بر

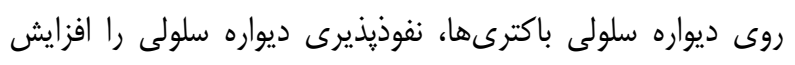

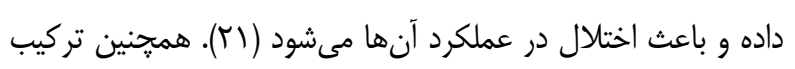

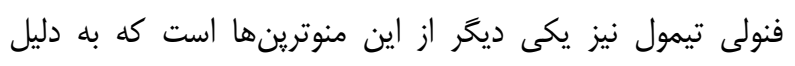




\section{نتيجه كيرى}

به طور كلى، نتايج به دست آمده در مطالعه حاضر نشان داد كه

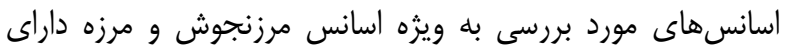

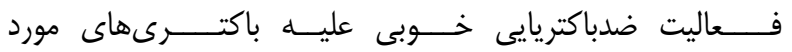

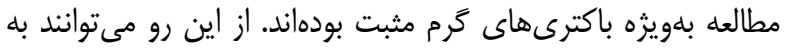

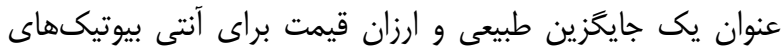

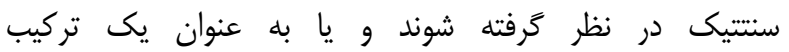

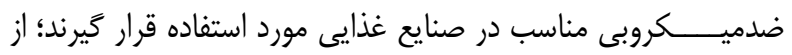

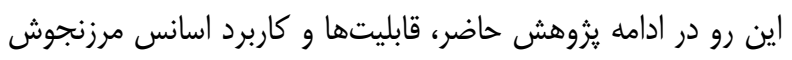

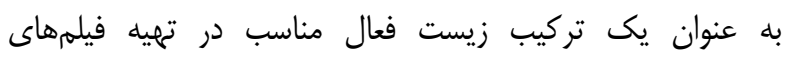

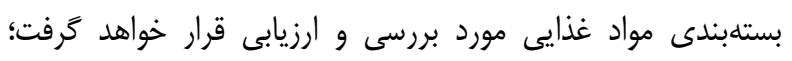

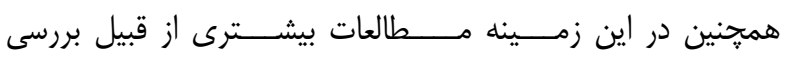
اثرات سميت سلولى اسانس در شرايط in vivo و مـــورد نيــاز است كه در تحقيقات آينــــه مـــــورد توجه قــــــــرار خواهد كرفت.

\section{تقدير و تشكّر}

اين مقاله مستخرج از ياياننامه دانشجو با كد رهخيرى

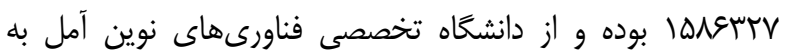
دليل همكارى در اجراى اين تحقيق تشكر و قدردانى به عمل مى آيد.

\section{تضاد منافع}

نويسندكان مقاله اعلام مىدارند كه هيج گَونه تضاد منافعى در

$$
\text { يزوهش حاضر وجود ندارد. }
$$

به دليل وجود ساختار لييويلى ساكاريدى (LPS) در غشاى خارجى باكترىهاى كرم منفى است. بخش بلى ساكاريدى موجود در ساختار

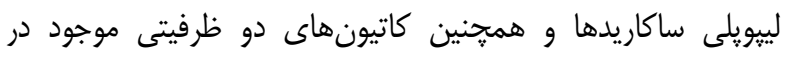
غشاى خارجى باكترىهاى كرم منفى داراى خاصيت آب دوست

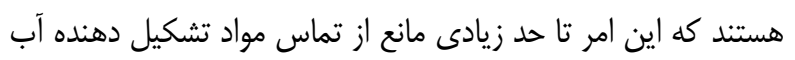

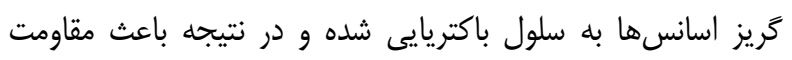

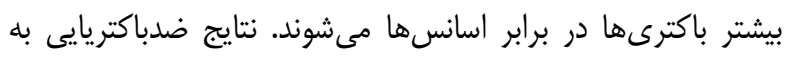

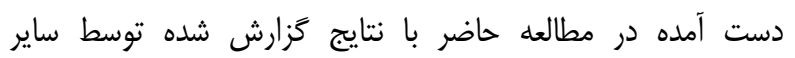

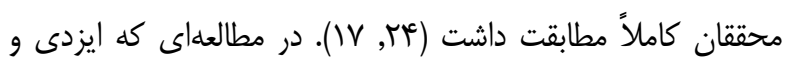

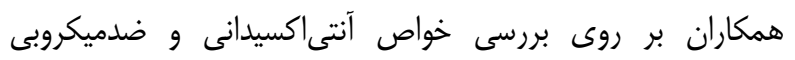

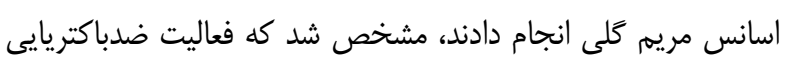

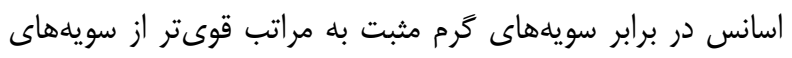

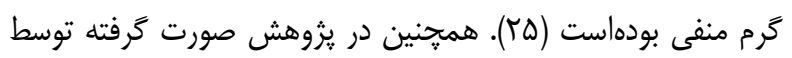
Zhou

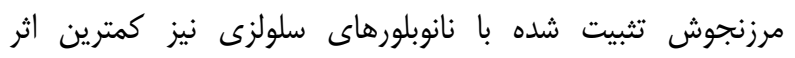
مهاركنندگى اسانس بر روى باكترى گرم منفى اشرشيا كلاى و

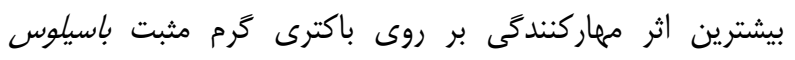

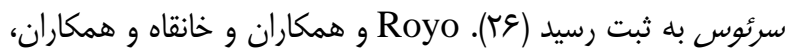
فعاليت ضدميكروبى اسانس مرزنجوش را به وجود تركيبات زيست

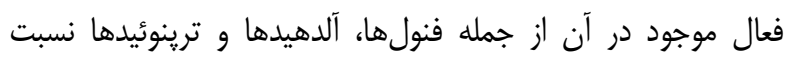

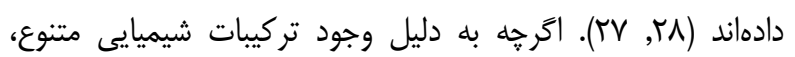
مكانيسم خاصى براى اثرات ضدباكتريايى اسانسها در نظر كرفته

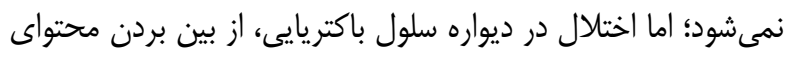
سلول، انعقاد در سيتويلاسم و همجنين اختلال در عملكرد انتقال

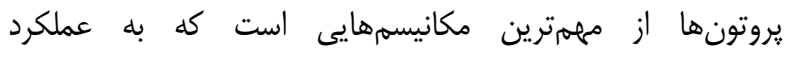

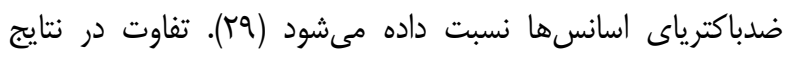

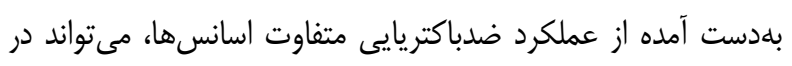

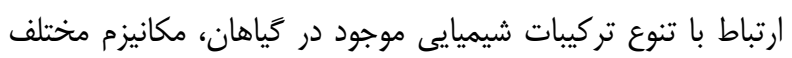

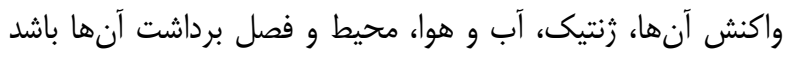




\section{منابع:}

1- El Asbahani A, Miladi K, Badri W, Sala M, Addi EA, Casabianca H,et al. Essential oils: from extraction to encapsulation. Int J Pharm. 2015; 483 (1-2): 220-43. Link

2- Fisher K, Phillips C. Potential antimicrobial uses of essential oils in food: is citrus the answer. Trends Food Sci Technol. 2008; 19(3): 156-64. DOI: 10.1016/j.tifs.2007.11.006

3- Sanches-Silva A, Costa D, Albuquerque TG, Buonocore GG, Ramos F, Castilho MC,et al. Trends in the use of natural antioxidants in active food packaging: a review. Food Addit Contam Part A Chem Anal Control Expo Risk Assess. 2014; 31(3): 374-95. DOI: 10.1080/19440049.2013.879215

4- Adelakun OE, Oyelade OJ, Olanipekun BF. Use of essential oils in food preservation. Essential oils in food preservation, flavor and safety. 2016; 71-84. DOI: https://doi.org/10.1016/B978-0-12-416641-7.00007-9

5- Shahidi F. Functional foods: their role in health promotion and disease prevention. J Food Sci. 2004; 69(5): R146-9. DOI: $10.1111 /$ j.1365-2621.2004.tb10727.x

6- Batiha GE, Beshbishy AM, Tayebwa DS, Shaheen HM, Yokoyama N, Igarashi I. Inhibitory effects of Syzygium aromaticum and Camellia sinensis methanolic extracts on the growth of Babesia and Theileria parasites. Ticks Tick Borne Dis. 2019; 10(5): 949-58. DOI: 10.1016/j.ttbdis.2019.04.016

7- Astuti RI, Listyowati S, Wahyuni WT. Life span extension of model yeast Saccharomyces cerevisiae upon ethanol derived-clover bud extract treatment. IOP Conf Ser Earth Environ Sci. 2019: 299(1): 012059. DOI: 10.1088/17551315/299/1/012059/meta

8- Khedher MR, Khedher SB, Chaieb I, Tounsi S, Hammami M. Chemical composition and biological activities of Salvia officinalis essential oil from Tunisia. EXCLI J. 2017; 16: 160-73. DOI: 10.17179\%2Fexcli2016-832

9- Rguez S, Msaada K, Daami-Remadi M, Chayeb I, Bettaieb Rebey I, Hammami M,et al. Chemical composition and biological activities of essential oils of Salvia officinalis aerial parts as affected by diurnal variations. Plant Biosystems. 2019; 153 (2): 264-72. DOI: 10.1080/11263504.2018.1473305

10- Efe D. Carbonic anhydrase enzyme inhibition and biological activities of Satureja hortensis L. essential oil. Ind Crops Prod. 2020; 156: 112849. https://doi.org/10.1016/j.indcrop.2020.112849

11- Elshafie HS, Camele I. Investigating the effects of plant essential oils on postharvest fruit decay. Fungal Pathogenicity; InTech: London, UK. 2016. P: 83-98. DOI: 10.5772/62568.

12- Bhat V, Sharma SM, Shetty V, Shastry CS, Rao CV, Shenoy S,et al. Characterization of herbal antifungal agent, Origanum vulgare against Oral Candida spp. isolated from patients with Candida-associated denture stomatitis: an in vitro study. Contemp Clin Dent. 2018; 9 (5): 3-10. DOI: 10.4103\%2Fccd.ccd_537_17

13- Ghanbari Hassan Kiadeh S, Rahaiee S, Azizi H, Govahi M. Evaluation of biological activities of raw and cooked Brassica oleracea sprout extracts rich in bioactive compound Sulforaphane. J Birjand Univ Med Sci. 2021; 28(3): 236-47. [Persian]. DOI: 10.32592/JBirjandUnivMedSci.2021.28.3.102

14- CLSI. Performance Standards for Antimicrobial Disk Susceptibility Tests, Approved Standard. 7th ed. CLSI document M02-A11. Clinical and Laboratory Standards Institute, 950 West Valley Road, Suite 2500, Wayne, Pennsylvania 19087, USA, 2012. Link

15- CLSI. Methods for Dilution Antimicrobial Susceptibility Tests for Bacteria That Grow Aerobically. 11th ed. CLSI document M07. Wayne, PA: Clinical and Laboratory Standards Institute; 2018. Link

16- Roginsky V and Lissi EA. Review of methods to determine chain-breaking antioxidant activity in food. Food Chem. 2005; 92(2): 235 - 54. DOI: 10.1016/j.foodchem.2004.08.004

17- Raeisi M, Hashemi M, Aminzare M, Sadeghi M, Jahani T, Keshavarzi H, et al. Comparative Evaluation of phytochemical, antioxidant, and antibacterial properties from the essential oils of four commonly consuming plants in Iran.J Food Qual Hazards Control. 2016; 3: 107-13. Link 
18- de la Fuente B, López-García G, Máñez V, Alegría A, Barberá R, Cilla A. Evaluation of the bioaccessibility of antioxidant bioactive compounds and minerals of four genotypes of Brassicaceae microgreens. Foods. 2019; 8(7): 250. DOI: $10.3390 /$ foods 8070250

19- Govahi M, Ghorbani F, Ranjbar M, Rahaiee S, Azizi H. Evaluation of Antioxidant and Antibacterial Activity, and Determination of Phenolic and Flavonoid Content of Aqueous and Methanolic Extracts of Scutellaria pekinensis. J Ilam Univ Med Sci.2019; 27(3): 91-100. [Persian] DOI: 10.29252/sjimu.27.3.91

20- Andi S, Nazeri V, Hadian J. A comparison of the essential oil chemical composition of Origanum vulgare L. ssp. vulgare collected in its flowering and seed stages from Southern region of Chalus. Iranian Journal of Horticultural Science. 2012; 43(2): 153-9. DOI: 10.22059/ijhs.2012.25107

21- Oskoueian E, Dalir M. A review of the most widely used medicinal plant active compounds and their effects on growth, health and production parameters in the poultry industry. Veterinary Researches \& Biological Products. 2019; 32(4): 2-12. DOI: 10.22092/vj.2019.124480.1537

22- Suntres ZE, Coccimiglio J, Alipour M. The bioactivity and toxicological actions of carvacrol. Critical reviews in food science and nutrition 2015; 55(3): 304-18. DOI: 10.1080/10408398.2011.653458

23- Moghri SA, Kiadeh SG, Rahaiee S. In silico investigation of lysostaphin-producing novel strains as an enzybiotic against methicillin-resistant Staphylococcus aureus. Inform Med Unlocked. 2021；24: 100623. DOI: 10.1016/j.imu.2021.100623

24- Abdollahzadeh E, Rezaei M, Hosseini H. Antibacterial activity of plant essential oils and extracts: The role of thyme essential oil, nisin, and their combination to control Listeria monocytogenes inoculated in minced fish meat. Food control. 2014; 35(1): 177-83. DOI: 10.1016/j.foodcont.2013.07.004

25- Izadi Z, Mirazi N. Identification of Chemical Compounds and Evaluation of Antioxidant and Antimicrobial Properties of Sage (Salvia officinalis L.) Essential Oil at Different Harvest Times.Qom Univ Med Sci J. 2020; 14(9): 1-15. [Persian] DOI: 10.52547/qums.14.9.1

26- Zhou Y, Sun S, Bei W, Zahi MR, Yuan Q, Liang H. Preparation and antimicrobial activity of oregano essential oil Pickering emulsion stabilized by cellulose nanocrystals. Int J Biol Macromol. 2018; 112: 7-13. DOI: 10.1016/j.ijbiomac.2018.01.102

27- Royo M, Fernández-Pan I, Maté JI. Antimicrobial effectiveness of oregano and sage essential oils incorporated into whey protein films or cellulose-based filter paper. J Sci Food Agric. 2010; 90(9): 1513-9. DOI: 10.1002/jsfa.3977

28- Khaneghah AM, Hashemi SM, Limbo S. Antimicrobial agents and packaging systems in antimicrobial active food packaging: An overview of approaches and interactions. Food Bioprod Process. 2018; 111: 1-19. DOI: 10.1016/j.fbp.2018.05.001

29- Bakkali F, Averbeck S, Averbeck D, Idaomar M. Biological effects of essential oils-a review. Food Chem Toxicol. 2008; 46(2): 446-75. DOI: 10.1016/j.fct.2007.09.106

30- Molodi F, Mahmoudi R, Rezaazdbari M. Chemical composition, antimicrobial and antioxidant Properties of essential oil of Origanum vulgar ssp. Gracile. J Babol Uni Med Sci. 2018; 20(10): 36-44. [Persian] DOI: 10.18869/acadpub.jbums.20.10.36 